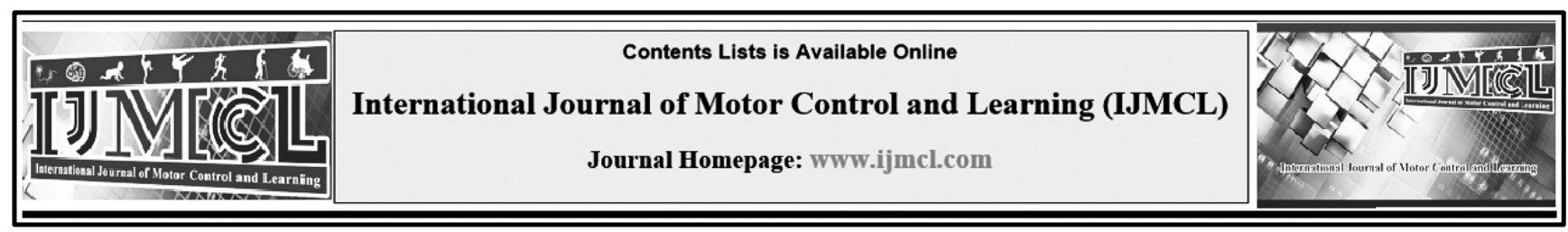

\title{
Comparison of Personality Characteristics of Athletes in Team and Individual Sport
}

\author{
Mahdi Mollazadeh ${ }^{a *}$, Hassan Gharayagh Zandi ${ }^{b}$, Mohammadjavad Rostamizadeh $^{c}$, Meysam Yavari Kateb $^{d}$

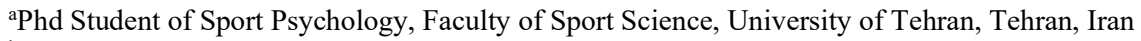 \\ bAssistant Professor of Sport Psychology, Faculty of Sport Science, University of Tehran, Tehran, Iran \\ ${ }^{\mathrm{c} M . S c .}$ Student of Sport Psychology, Faculty of Sport Science, University of Tehran, Tehran, Iran \\ ${ }^{\mathrm{d}}$ M.Sc. Student of Sport Psychology, Faculty of Sport Science, University of Tehran, Tehran, Iran
}

\begin{tabular}{|c|c|}
\hline Keywords & Abstract \\
\hline Athletes & Objective: In this study, personality characteristics of neuroticism, extraversion, \\
\hline Neuroticism & and openness to new experiences, consensus, and task of male and female athletes \\
\hline Extraversion & were compared in team and individual sports. \\
\hline Onenness & Methods: 160 athletes (13 athletes dropped out) were selected from professional \\
\hline Openness & athletes in two disciplines ( 75 men: 39 men and 36 women) and group ( 72 men: 41 \\
\hline Moldi Mollorado & $\begin{array}{l}\text { men and } 31 \text { women) in Kerman province. The athletes were asked to complete the } \\
\text { NEO-FFI questionnaire for } 60 \text { questions. For data analysis, descriptive statistics } \\
\text { including mean and standard deviations and inferential statistics: independent t-test } \\
\text { were used. }\end{array}$ \\
\hline $\begin{array}{l}\text { Mahdi Mollazadeh, } \\
\text { Email: Mahdi.Mollazadeh@ut.ac.ir }\end{array}$ & $\begin{array}{l}\text { Results: The findings of the study showed that the athletes' score in group sports in } \\
\text { agreement, extraversion and task is significantly higher than individual sports. }\end{array}$ \\
\hline Received: 2019/11/01 & $\begin{array}{l}\text { Individual athletes had a high risk of neuroticism, and athletes had a lower score } \\
\text { than men in all of the components except for neuroticism. }\end{array}$ \\
\hline Accepted: 2020/01/19 & Conclusion: It can be concluded that personality characteristics of male and female \\
\hline Published: 2020/02/18 & $\begin{array}{l}\text { athletes and team and individual athletes are different. It is hoped that this research } \\
\text { will be conducted in different ages, communities and disciplines, and the results } \\
\text { will be reported. }\end{array}$ \\
\hline
\end{tabular}

\section{Introduction}

Examining the relationship between sport and personality traits is another field of research (Tafti, Pakdaman, \& Asgari, 2008), but few studies have been done on the psychological mechanisms of personality traits on health behaviors (Bermúdez, 1999; Hoyle, 2000). Although little evidence exists to support the existence of a specific sports personality, the personality characteristics of the elite athletes are different from those of nonathletes as well as those related to each discipline
(Gill, 1986). Cologne 2013 believes that sporting success in any race and discipline is not possible without proper mental state (Kleanthous et al., 2013). Galway 2012 stated that many factors, such as learning problems, educational levels, age, gender, and personality characteristics, are generally effective in determining the success of most exercises. (Galloway, 2010) In addition, the study of Mary I of 1940 showed that motor ability is related to personality traits (Merriman, 1960). 
In the last two decades, the Five Factors (NEOFFM) have transformed character into a dominant psychology pattern (Allik, 2002). The 5-factor model of personality includes aspects of neuroticism, extroversion, experience, consensus, and conscientiousness. Neuroticism, the sensitivity of the sensation lies in a wide range of emotions and negative feelings such as discomfort, irritability, tension, and so on. The openness of experiences is related to the depth and complexity of the thoughts and minds and experiences of that person (Saulsman \& Page, 2004). Task or conscience consists mainly of targeted behavioral attributes and impact control in a way that is socially acceptable (McGhee, Ehrler, \& Buckhalt, 2007). Extraversion and an agreement that is related to personality behaviors is a person's identity (Fruyt, McCrae, Szirmák, \& Nagy, 2004).

Research studies (Conner \& Abraham, 2001; Courneya, Bobick, \& Schinke, 1999; Courneya \& Hellsten, 1998; Fruyt et al., 2004; Marks \& Lutgendorf, 1999; Rhodes, Courneya, \& Bobick, 2001) have investigated the relationship between the 5-factor model of personality and athletic activities that sport activity with less neuroticism, extraversion and task. Several researches in the context of the 3D model of personality have shown that exercise activity with one or more personality dimensions is more correlated with neuroticism and lower psychosis and extraversion (Davis, Elliott, Dionne, \& Mitchell, 1991; Davis \& Fox, 1993; Fruyt et al., 2004; Potgieter \& Venter, 1995; Yeung \& Hemsley, 1997). Having different degrees of personality traits affects emotions, feedback, and behaviors, for example, those who score in the neuro-psychiatric dimension more than the softness, are more readily prepared to experience the thrill of fear, sadness, confusion, anger and guilt are (Bolger \& Schilling, 1991; David, Green, Martin, \& Suls, 1997; Watson \& Clark, 1992).

There is a significant difference between psychological skills and the motivation for sport success between two groups (individual and team), but there is no significant difference in emotional intelligence between two groups (individual and team) (Kajbafnezhad, Ahadi, Heidarie, Askari, \& Enayati, 2011). Today, sports psychologists recognize the athlete's athletic success in relation to their personality (Lopez \& Santelices, 2012) Avilli et al., 1993, concluded that there was a positive relationship between the personality and the athlete's functional aspects (Vanden Auweele, De Cuyper, Van Mele, \& Rzewnicki, 1993). And even the instructors initially identified players based on The psychological list of their capabilities to predict success (Horn, 2008). Studying the recognition of personality characteristics of athletes, both individual and team, enables sports psychologists and trainers to provide the best advice in finding talent. Materials provided by the research need to be conducted. Accordingly, the main purpose of this study is to analyze and identify personality characteristics of athletes in team and individual sports (Handball and Ping Pong). 


\section{Method}

The statistical population of this study was 160 people and were optimistically comparable that 13 of the questionnaires were excluded from the statistical society due to lack of correct completion, selection of more than one option, and failure to submit it. This study was conducted on adult Handball players and professional ping-pong players in Kerman province in 1996, in which 72 handball players ( 31 girls and 41 boys) and pingpong (75) (36 boys 39 boys) were involved. The age range of athletes was between 18 and 30 years old. Measurement tool for Athletes' personality NEO-FFI 60 questions to measure 5 nonlinear factors, extraversion, experience, consensus, and task based on Likert scale (I totally disagree, to totally agree). The reported alpha coefficient of the five-factor NEO-FFI questionnaire by McGeery and Costa was between 0.44 and 0.89 with a mean of 0.81 (Costa \& McCrae, 1992). The alpha coefficient for neuroticism is 0.85 , extraversion 0.78 , openness to experiences 0.87 , agreement of 0.90 and for conscientiousness or conscientiousness of 0.83 , indicating a high internal consistency of the questionnaire (Costa \& McCrae, 1992). This questionnaire was translated by Dr. Grossi Farshi in Persian and standardized for
Iranian students. In Iran, the reliability coefficient for routine components was 0.83 , extraversion 0.75, experiencing 80.0, agreement 0.79 , and conscientiousness 79/9 (Garusi, 1998).

Descriptive statistics including mean, standard deviation, and for comparison between groups of independent t-test were used.

\section{Results}

Table 1 shows the mean and standard deviations of athletes' scores for personality characteristics of neuroticism, extraversion, openness, consensus, and conscientiousness.

Independent t-test was used to compare the scores of personality traits such as neuroticism, extraversion, and openness of experiences, agreement and attitude of athletes in individual and group exercises. The results of t-test showed that the score of athletes in individual exercises in the variables of neuroticism and openness of experiences was significant $(\mathrm{P}<0.05)$ more than the score of athletes in group sports in these variables. These results also showed that the score of athletes in group sports in extraversion, agreement, and conscientiousness variables was significantly $(\mathrm{P}<0.05)$ higher than that of individual athletes in these variables (Table 2).

Table 1. Average and standard deviations of personality traits scores of neuroticisms, extraversion, openness of experiences, Agreeableness and conscientiousness of athletes in individual and group sports.

\begin{tabular}{llcc}
\hline $\begin{array}{l}\text { Index/ } \\
\text { Variable }\end{array}$ & $\begin{array}{c}\text { All sports } \\
\text { M (SD) }\end{array}$ & $\begin{array}{c}\text { Group sports } \\
\text { M (SD) }\end{array}$ & $\begin{array}{c}\text { Individual sports } \\
\text { M (SD) }\end{array}$ \\
\hline Neuroticism & $21.41(6.87)$ & $19.79(7.20)$ & $22.96(6.19)$ \\
Extraversion & $28.65(5.88)$ & $29.72(5.49)$ & $27.61(6.08)$ \\
Openness & $25.07(4.78)$ & $23.18(4.69)$ & $26.89(4.13)$ \\
Agreeableness & $30.60(6.00)$ & $33.24(5.21)$ & $28.07(5.62)$ \\
Conscientiousness & $35.32(5.72)$ & $36.35(5.27)$ & $34.33(6.00)$ \\
\hline
\end{tabular}


Table 2. T-test results for comparing the scores of personality traits of neuroticism, extraversion, and openness of experiences, agreement and task of athletes in individual and group sports

\begin{tabular}{|c|c|c|c|c|c|c|c|}
\hline Variable & $\begin{array}{c}\text { Index/ } \\
\text { Group } \\
\end{array}$ & $\mathbf{N}$ & $\mathbf{M}$ & SD & df & $\mathbf{T}$ & $\mathbf{P}$ \\
\hline \multirow{2}{*}{ Neuroticism } & Individual sports & 75 & 22.96 & 6.19 & \multirow{2}{*}{145} & \multirow{2}{*}{2.86} & \multirow{2}{*}{.005} \\
\hline & Group sports & 72 & 19.79 & 7.20 & & & \\
\hline \multirow{2}{*}{ Extraversion } & Individual sports & 75 & 27.61 & 6.08 & \multirow{2}{*}{145} & \multirow{2}{*}{-2.20} & \multirow{2}{*}{.029} \\
\hline & Group sports & 72 & 29.72 & 5.49 & & & \\
\hline \multirow{2}{*}{ Openness } & Individual sports & 75 & 26.89 & 4.13 & \multirow{2}{*}{145} & \multirow{2}{*}{5.09} & \multirow{2}{*}{.000} \\
\hline & Group sports & 72 & 23.18 & 4.69 & & & \\
\hline \multirow{2}{*}{ Agreeableness } & Individual sports & 75 & 28.07 & 5.62 & \multirow{2}{*}{145} & \multirow{2}{*}{-5.77} & \multirow{2}{*}{.000} \\
\hline & Group sports & 72 & 33.24 & 5.21 & & & \\
\hline \multirow{2}{*}{ Conscientiousness } & Individual sports & 75 & 34.33 & 6.00 & \multirow{2}{*}{145} & \multirow{2}{*}{-2.15} & \multirow{2}{*}{.033} \\
\hline & Group sports & 72 & 36.35 & 5.27 & & & \\
\hline
\end{tabular}

In this study, the scores of personality characteristics of neuroticism, extraversion, openness of experiences, agreement and attitude of athletes among female athletes and male athletes were compared. Independent t-test was used for evaluation. The results of t-test showed that male athlete's score in extraversion variables, openness of experiences, agreement, and conscientiousness are higher than female athletes in these variables. These differences were significant only in extraversion variables, openness of experiences and agreement $(\mathrm{P}<0.05)$. Also, female athletes score was significantly $(\mathrm{p}<0.05)$ higher than that of male athletes in the variable in neuroticism (Table 3).

Table 3. Results of $t$ test for comparing the scores of personality characteristics of neuroticism, extraversion, and openness of experience, agreement and task of male and female athletes.

\begin{tabular}{|c|c|c|c|c|c|c|c|}
\hline Variable & $\begin{array}{l}\text { Index/ } \\
\text { Group }\end{array}$ & $\mathbf{N}$ & $\mathbf{M}$ & SD & df & $\mathbf{T}$ & $\mathbf{P}$ \\
\hline \multirow{2}{*}{ Neuroticism } & Male athletes & 80 & 20.33 & 6.84 & 145 & -2.11 & .036 \\
\hline & Female athlete & 67 & 22.70 & 6.72 & & & \\
\hline \multirow{2}{*}{ Extraversion } & Male athletes & 80 & 29.91 & 5.69 & 145 & 2.92 & .004 \\
\hline & Female athlete & 67 & 27.13 & 5.87 & & & \\
\hline \multirow{2}{*}{ Openness } & Male athletes & 80 & 25.81 & 4.71 & 145 & 2.06 & .041 \\
\hline & Female athlete & 67 & 24.19 & 4.75 & & & \\
\hline \multirow{2}{*}{ Agreeableness } & Male athletes & 80 & 31.78 & 6.13 & 145 & 2.65 & .009 \\
\hline & Female athlete & 67 & 29.19 & 5.55 & & & \\
\hline \multirow{2}{*}{ Conscientiousness } & Male athletes & 80 & 36.11 & 4.92 & 145 & 1.80 & .074 \\
\hline & Female athlete & 67 & 34.37 & 6.47 & & & \\
\hline
\end{tabular}

\section{Discussion}

The findings of the study showed that the mean scores of athletes in the personality characteristics of extraversion and task is relatively more and in neuroticism less than the average score of nonathlete subjects reported in other studies. This research finding, which is consistent with earlier studies (Conner \& Abraham, 2001; Davis et al., 1991; Davis \& Fox, 1993; Fruyt et al., 2004; Potgieter \& Venter, 1995), is expressed as follows: exercise has provided not only happiness, vitality, liveliness, more activity but also less fear anxiety, depression, and discomfort (Bolger \& Schilling, 1991; David et al., 1997; Watson \& Clark, 1992). 
These findings are related to the personality traits of routine and extraversion that are more common in athletes than non-athletes(Haghi, 2014) and increase their participation(Kökény, 2018). These findings can be explained by the fact that personality components add more extraversion and less personality roles in sporting activities. And so, people who go into sports, whether in groups or individually, provide a platform for the dynamics and realization of these features.

In the case of more agreeable team sports athletes, compared to individual sports athletes, one of the findings of the present research is that trust is one of the components of the agreement. Trust as a personal relationship helps people to rely on others and expand interpersonal relationships and activities, in addition to be willing to participate actively in group and community relationships and activities more easily and reliably. Group exercises are one of the most suitable areas for realizing this feature. On this basis, it can be said that an agreement in terms of individual trust is more conducive to group exercise, and this justifies the agreement between the athletes of the group's sports in comparison with the agreement of the individual athletic players. Another aspect of agreement is adherence. This component enables a person to get closer to others. This attributes the individual's personality to group activities, and this justifies the difference in agreement between athletes in individual and team sports. Friendship is also another component of an agreement that prepares a person for helping and loving others, and prepares a person to help his or her own group and group activities. Therefore, these personality traits are not satisfied with individual sports, and requires a context like group sports, and these statements are aligned with the findings of this research and Besharat (2010). All three components of the agreement, namely, altruism, adherence, and trust in the form of an agreement, reinforce participation in team activities, and lead individuals to choose team sports instead of individual exercises.

In this research, the athletes in group sports scored higher than those in individual sports in extroversion, which is incompatible with the research of Colley (1985) and with the research of Nia (2010) and Kshetrimayum (2017) (Kökény, 2018; Kshetrimayum, 2017; Nia \& Besharat, 2010). In explaining this, it can be said that sporting activities provide a good environment for individuals to get extroverted and to communicate with each other. In conscientiousness, athletes in group sports scored higher than those in individual sports. This component can be explained by the fact that sport, with the help of teamwork and group work, identifies the tasks of each individual, and the athlete learns conscientiousness by participating in it. In fact, the athlete's conscientiousness is indispensable for the success of group sports. But in terms of neuroticism and openness of experiences, athletes in individual sports gain high scores in comparison to group sports(Nia \& Besharat, 2010).

This explains the findings that in group sports, people are more extroverted and agreeable, and less open to experiences and less neurotic. 
Extroverted athletes who are emotionally stable and welcome new experiences have reported that they are better off using coping strategies to solve their problems. Athletes who are conscientious, open to experience and agree with others have been reported to have a better coping strategy to focus on, and athletes who have a low or lower level of openness to experiences and or a high score of neuroticisms has been reported that avoid coping strategies. Different personality characteristics are observed between male and female athletes or teams and individuals who have a high or low score. The NEO 5-person personality model can help determine the levels of athletic conflicts or participation in a sport program (Allen, Greenlees, \& Jones, 2011).

\section{Conclusions}

Differences in personality characteristics of men and women also show that male athletes are more extroverted, agreeable, open to experience, and conscientious than female ones, and females are more likely than males to have a higher score in neuroticism. These findings justify the participation and success of males in sport more than females.

The findings of this study will be useful for different reasons for sport psychology. At the scientific level, recognizing personality traits for decision making and investing and choosing a sports discipline will be useful to sports psychologists, coaches, and athletes. Also, the development of interventional programs to change the necessary attributes affecting further fitness training based on these findings is also the result of scientific research. It is hoped to look at this issue from the aspects of age, community and in different field and disciplines.

\section{Limitations and delimitations}

One of the limitations of this research is the lack of simultaneous examination of possible intermediary variables.

\section{References}

1. Allen, M. S., Greenlees, I., \& Jones, M. (2011). An investigation of the five-factor model of personality and coping behaviour in sport. Journal of sports sciences, 29(8), 841-850.

2. Allik, I. U. (2002). The five-factor model of personality across cultures: Springer Science \& Business Media.

3. Bermúdez, J. (1999). Personality and healthprotective behaviour. European journal of personality, 13(2), 83-103.

4. Bolger, N., \& Schilling, E. A. (1991). Personality and the problems of everyday life: The role of neuroticism in exposure and reactivity to daily stressors. Journal of Personality, 59(3), 355-386.

5. Conner, M., \& Abraham, C. (2001). Conscientiousness and the theory of planned behavior: Toward a more complete model of the antecedents of intentions and behavior. Personality and Social Psychology Bulletin, 27(11), 1547-1561.

6. Costa, P. T., \& McCrae, R. R. (1992). Revised $N E O$ personality inventory (NEO PI-R) and NEP five-factor inventory (NEO-FFI): professional manual: Psychological Assessment Resources Lutz, FL.

7. Courneya, K. S., Bobick, T. M., \& Schinke, R. J. (1999). Does the theory of planned behavior mediate the relation between personality and exercise behavior? Basic and Applied Social Psychology, 21(4), 317-324.

8. Courneya, K. S., \& Hellsten, L.-A. M. (1998). Personality correlates of exercise behavior, motives, barriers and preferences: An application of the five-factor model. Personality and Individual differences, 24(5), 625-633.

9. David, J. P., Green, P. J., Martin, R., \& Suls, J. (1997). Differential roles of neuroticism, 
extraversion, and event desirability for mood in daily life: An integrative model of top-down and bottom-up influences. Journal of personality and social psychology, 73(1), 149.

10. Davis, C., Elliott, S., Dionne, M., \& Mitchell, I. (1991). The relationship of personality factors and physical activity to body satisfaction in men. Personality and Individual differences, 12(7), 689694.

11. Davis, C., \& Fox, J. (1993). Excessive exercise and weight preoccupation in women. Addictive Behaviors, 18(2), 201-211.

12. Fruyt, F. D., McCrae, R. R., Szirmák, Z., \& Nagy, J. (2004). The five-factor personality inventory as a measure of the five-factor model: Belgian, American, and Hungarian comparisons with the NEO-PI-R. Assessment, 11(3), 207-215.

13. Galloway, J. (2010). Cross-Country Running \& Racing: Meyer \& Meyer Verlag.

14. Garusi, M. (1998). Normalization and validation of NEO-FFI inIranian university students. Ph. D dissertation. Tarbiyat Modarres University.

15. Gill, D. (1986). Psychology dynamics of sport. Champaingn: Humann kinetics.

16. Haghi, P. M. A. M. (2014). The comparison of five personality factors between athlete and non-athlete students. Indian Journal of Science and Research, 3(1), 350-354.

17. Horn, T. S. (2008). Advances in sport psychology: Human Kinetics.

18. Hoyle, R. H. (2000). Personality processes and problem behavior. Journal of Personality, 68(6), 953-966.

19. Kajbafnezhad, H., Ahadi, H., Heidarie, A. R., Askari, P., \& Enayati, M. (2011). Difference between team and individual sports with respect to psychological skills, overall emotional intelligence and athletic success motivation in Shiraz city athletes. Journal of Physical Education and Sport, 11(3), 249.

20. Kleanthous, S., Savvides, C., Christofides, I., Hadjimitsis, D. G., Themistocleous, K., Achilleos, C., . . . Douros, I. (2013). Particulate monitoring, modeling, and management: natural sources, long-range transport, and emission control options: a case study of Cyprus. Paper presented at the First International Conference on Remote Sensing and Geoinformation of the Environment (RSCy2013).

21. Kökény, L. (2018). Doing sports-Is it influenced by your personality. Proceedings of The 12th MAC 2018, 127.

22. Kshetrimayum, A. (2017). A. Kshetrimayum, H. Weimer, and R. Orús, Nat. Commun. 8, 1291 (2017). Nat. Commun., 8, 1291.
23. Lopez, A., \& Santelices, O. (2012). Personality characteristics of elite table tennis athletes of the Philippines: basis for a proposed recruitment program. International Journal of Table Tennis Sciences, 7, 1-4.

24. Marks, G. R., \& Lutgendorf, S. K. (1999). Perceived health competence and personality factors differentially predict health behaviors in older adults. Journal of Aging and health, 11(2), 221-239.

25. McGhee, R. L., Ehrler, D. J., \& Buckhalt, J. A. (2007). FFPI-C: Five-factor Personality Inventory-Children: Pro-Ed.

26. Merriman, J. B. (1960). Relationship of personality traits to motor ability. Research Quarterly. American Association for Health, Physical Education and Recreation, 31(2), 163173.

27. Nia, M. E., \& Besharat, M. A. (2010). Comparison of athletes' personality characteristics in individual and team sports. Procedia-Social and Behavioral Sciences, 5, 808-812.

28. Potgieter, J. R., \& Venter, R. E. (1995). Relationship between adherence to exercise and scores on extraversion and neuroticism. Perceptual and Motor Skills, 81(2), 520-522.

29. Rhodes, R. E., Courneya, K. S., \& Bobick, T. M. (2001). Personality and exercise participation across the breast cancer experience. PsychoOncology, 10(5), 380-388.

30. Saulsman, L. M., \& Page, A. C. (2004). The fivefactor model and personality disorder empirical literature: A meta-analytic review. Clinical psychology review, 23(8), 1055-1085.

31. Tafti, N. N., Pakdaman, S., \& Asgari, A. (2008). The role of sport and personality traits in psychosocial development of students. Journal of Iranian Psychologist, 5, 53-62.

32. Vanden Auweele, Y., De Cuyper, A., Van Mele, V., \& Rzewnicki, R. (1993). Elite performance and personality: from description and prediction to diagnosis and intervention.

33. Watson, D., \& Clark, L. A. (1992). On traits and temperament: General and specific factors of emotional experience and their relation to the fivefactor model. Journal of Personality, 60(2), 441476.

34. Yeung, R. R., \& Hemsley, D. R. (1997). Personality, exercise and psychological wellbeing: Static relationships in the community. Personality and Individual Differences, 22(1), 4753. 